\title{
Flexural strength and hardness of direct and indirect composites
}

\section{Márcia Borba (a) \\ Álvaro Della Bona ${ }^{(b)}$ Dileta Cecchetti ${ }^{(c)}$}

(a) PhD Student, Dental Materials, University of São Paulo, SP, Brazil.

(b) $\mathrm{PhD}$ in Biomaterials, Research Coordinator and Senior Professor of Prosthodontics and Occlusion, Dental School, University of Passo Fundo, RS, Brazil.

(c) MSc in Statistics, Professor, Institute of Biological Sciences, University of Passo Fundo, RS, Brazil.

\author{
Corresponding author: \\ Álvaro Della Bona \\ Faculdade de Odontologia, Universidade \\ de Passo Fundo, Campus I, B. São José, BR \\ 285, Km 171 \\ Passo Fundo - RS - Brazil \\ CEP: 99001-970 \\ E-mail:dbona@upf.br
}

Abstract: The objective of this study was to evaluate the flexural strength $\left(\sigma_{\mathrm{f}}\right)$ and hardness $(\mathrm{H})$ of direct and indirect composites, testing the hypotheses that direct resin composites produce higher $\sigma_{\mathrm{f}}$ and $\mathrm{H}$ values than indirect composites and that these properties are positively related. Ten bar-shaped specimens ( $25 \mathrm{~mm} \times 2 \mathrm{~mm} \times 2 \mathrm{~mm})$ were fabricated for each direct [D250 - Filtek Z250 (3M-Espe) and D350 - Filtek Z350 (3MEspe)] and indirect [ISin - Sinfony (3M-Espe) and IVM - VitaVM LC (Vita Zahnfabrik)] materials, according to the manufacturer's instructions and ISO4049 specifications. The $\sigma_{\mathrm{f}}$ was tested in three-point bending using a universal testing machine (EMIC DL 2000) at a crosshead speed of $0.5 \mathrm{~mm} / \mathrm{min}$ (ISO4049). Knoop hardness (H) was measured on the specimens' fragments resultant from the $\sigma_{\mathrm{f}}$ test and calculated as $\mathrm{H}=14.2 \mathrm{P} / \mathrm{l}^{2}$, where $\mathrm{P}$ is the applied load $(0.1 \mathrm{~kg}$; dwell time $=15 \mathrm{~s})$ and $\mathrm{l}$ is the longest diagonal of the diamond shaped indent (ASTM E384). The data were statistically analyzed using Anova and Tukey tests $(\alpha=0.05)$. The mean $\sigma_{\mathrm{f}}$ and standard deviation values $(\mathrm{MPa})$ and statistical grouping were: D250 - $135.4 \pm 17.6 \mathrm{a}$; D350 - $123.7 \pm 11.1 \mathrm{~b}$; ISin - $98.4 \pm 6.4 \mathrm{c}$; IVM $-73.1 \pm 4.9 \mathrm{~d}$. The mean $\mathrm{H}$ and standard deviation values $\left(\mathrm{kg} / \mathrm{mm}^{2}\right)$ and statistical grouping were: D250 - $98.12 \pm 1.8 \mathrm{a}$; D350 - 86.5 $\pm 1.9 \mathrm{~b}$; ISin $-28.3 \pm 0.9$ c; IVM $-30.8 \pm 1.0$ c. The direct composite systems examined produce higher mean $\sigma_{\mathrm{f}}$ and $\mathrm{H}$ values than the indirect composites, and the mean values of these properties were positively correlated $(r=0.91)$, confirming the study hypotheses.

Descriptors: Composite resins; Dental materials; Hardness. 


\section{Introduction}

The development of adhesive materials and techniques represents an improvement for the use of indirect restorations, encouraging the research for materials with mechanical and esthetic properties more similar to those of the tooth structure. Indirect composite resin systems represent an alternative to overcome some deficiencies of direct composite restorations, such as polymerization shrinkage stresses, inadequate polymerization in interproximal areas, restoration of proximal contacts and adequate dental contour. ${ }^{1,2,3}$

The composition of indirect composite resin systems is similar to that of direct systems, differing by the use of different methods of additional polymerization, which allows a higher radical conversion. These additional polymerization procedures can involve photo-activation, heat, pressure, and a nitrogen atmosphere. ${ }^{3,4,5}$

In the early 1980's, the composite inlay technique was introduced in Switzerland and France. The first generation of materials was constituted of microfilled indirect composite resin systems, with flexural strength ranging from 60 to $80 \mathrm{MPa}$, elastic modulus around 2.0-3.5 GPa, resin volume percentage higher than $50 \%$ and microparticles with an average size of $0.04 \mu \mathrm{m}$. These features resulted in some disadvantages such as inadequate mechanical properties, low resistance to occlusal wear and color instability. ${ }^{2,3}$

The second generation of indirect composite resin systems was introduced in the 1990's. These materials are microhybrid composites with a volume percentage of inorganic fillers of approximately $66 \%$, resulting in improved mechanical properties with flexural strength between 120 and $160 \mathrm{MPa}$ and elastic modulus of 8.5-12 GPa. These systems are indicated for inlays and onlays, laminated veneers and jacket crowns, implant-support restorations, for adjustment of proximal contacts and for reduction of occlusal stresses in bruxism cases. ${ }^{2,3}$

Other indirect composite systems recently introduced, despite their excellent esthetics, are not classified as second-generation systems because they do not feature all of the required characteristics, like high mechanical properties values, high percentage of inorganic content and bond to metal. ${ }^{2,3}$ These composites are denominated intermediate laboratory composite resins. They have only a few properties of the second-generation composites but still can be effectively used in specific clinical situations. ${ }^{3}$

The indirect composite system Sinfony (3MESPE) is a microhybrid material developed to be applied using the layering technique because of its flow consistence. According to the manufacturer, this material is indicated for inlays and onlays, veneers and full crowns. This system needs two polymerization phases: an initial polymerization using the Visio Alfa unit (3M-ESPE) for $15 \mathrm{~s}$ for each layer, which reduces shrinkage stress; and a final polymerization under light and vacuum using the Visio Beta Vario unit (3M-ESPE) for $15 \mathrm{~min}$, which allows a higher monomer-polymer conversion.

The new system from Vita, Vita VM LC, is a light-curing microparticle indirect composite that can be used for the full and partial veneering of crowns, and as long-term temporary metal-free restorations. According to the manufacturer, this system is composed of inorganic nano-sized fillers that ensure high translucency due to natural refraction. The light curing box must be equipped with a light source which has a wavelength of 350-500 nm.

The objective of this study was to evaluate the flexural strength $\left(\sigma_{f}\right)$ and hardness $(\mathrm{H})$ of direct and indirect composites, testing the hypotheses that direct resin composites produce higher flexural strength and hardness values than indirect composites and that these properties are positively related.

\section{Material and Methods}

For the three-point flexural strength test, 10 barshaped specimens were fabricated from each direct and indirect composite system (Table 1), following the manufacturer's instructions and the ISO4049 specification. ${ }^{7}$ The composite resin was packed inside a stainless steel mold positioned on a glass slab to obtain the required dimensions $(2 \pm 0.1 \mathrm{~mm} x$ $2 \pm 0.1 \mathrm{~mm} \times 25 \pm 2 \mathrm{~mm}$ ). A thin glass slab was positioned on the mold containing the material, which was light cured. The upper and lower surfaces of the D250 and D350 specimens were light cured (XL1500, 3M Dental Products, St. Paul, MN, USA; intensity of 
Table 1 - Information on the composite resin systems investigated in this study.

\begin{tabular}{l|l|l|l|l}
\hline $\begin{array}{c}\text { Composite } \\
\text { resin }\end{array}$ & \multicolumn{1}{|c|}{ Material (manufacturer) } & Shade, batch & $\begin{array}{l}\text { Composition of the } \\
\text { organic matrix* }\end{array}$ & \multicolumn{1}{c}{ Composition of the filler content* } \\
\hline D250 & $\begin{array}{l}\text { Filtek Z250 (3M-Espe, St. Paul, } \\
\text { MN, USA) }\end{array}$ & A2, 5CB & $\begin{array}{l}\text { Bis-GMA, UDMA, } \\
\text { Bis-EMA, TEGDMA }\end{array}$ & $\begin{array}{l}\text { Zirconia and silica }(0.01-3.5 \mu \mathrm{m})-82 \% \text { by } \\
\text { weight }\end{array}$ \\
\hline D350 & $\begin{array}{l}\text { Filtek Z350 (3M-Espe, St. Paul, } \\
\text { MN, USA) }\end{array}$ & A2, 5BK & $\begin{array}{l}\text { Bis-GMA, UDMA, } \\
\text { Bis-EMA, TEGDMA }\end{array}$ & $\begin{array}{l}\text { Zirconia/silica filler }(0.6-1.4 \mu \mathrm{m}) \text { and } \\
\text { nanoparticles of silica }(20 \mathrm{~nm})-78.5 \% \text { by weight }\end{array}$ \\
\hline ISin & $\begin{array}{l}\text { Sinfony (3M-Espe, St. Paul, MN, } \\
\text { USA) }\end{array}$ & A2, 210476 & Bis-GMA & $\begin{array}{l}\text { Aluminum glass and } \mathrm{SiO}_{2}(0.6 \mu \mathrm{m})-50 \% \text { by } \\
\text { weight } 6\end{array}$ \\
\hline IVM & $\begin{array}{l}\text { Vita VM LC (Vita Zahnfabrik, } \\
\text { Bad Sackingen, Germany) }\end{array}$ & A2,7553 & & 45-48\% by weight \\
\hline
\end{tabular}

* The composition of the organic matrix and fillers was provided by the manufacturers.

Table 2 - Mean and standard deviation values of flexural strength $\left(\sigma_{f}\right)$ and hardness $(H)$, and statistical grouping.

\begin{tabular}{c|c|c}
\hline Groups & $\sigma_{f}(\mathrm{MPa})$ & $\mathrm{H}\left(\mathrm{kg} / \mathrm{mm}^{2}\right)$ \\
\hline D250 & $135.4 \pm 17.6 \mathrm{~A}$ & $98.1 \pm 1.8 \mathrm{a}$ \\
\hline D350 & $123.7 \pm 11.1 \mathrm{~B}$ & $86.5 \pm 1.9 \mathrm{~b}$ \\
\hline ISin & $98.4 \pm 6.4 \mathrm{C}$ & $28.3 \pm 0.9 \mathrm{c}$ \\
\hline IVM & $73.1 \pm 4.9 \mathrm{D}$ & $30.8 \pm 1.0 \mathrm{c}$ \\
\hline
\end{tabular}

Mean values followed by the same letter in each column are not statistically different by Tukey's test $(p \geq 0.05)$.

$400 \mathrm{~mW} / \mathrm{cm}^{2}$ ) for $40 \mathrm{~s}$ per unit output diameter. The polymerization procedure of the indirect composite systems followed the manufacturer's instructions. ISin was first light cured with a halogen lamp with intensity of $400 \mathrm{~mW} / \mathrm{cm}^{2}$ (Visio Alfa unit, 3M-ESPE) for $15 \mathrm{~s}$, and finally cured under light and vacuum (Visio Beta Vario unit, 3M-ESPE) for $15 \mathrm{~min}$. The IVM specimens were first light cured following the direct composite procedure and finally cured in 2 cycles of 4 min using a polymerization box (EDGLUX, EDG Equipamentos, São Carlos, SP, Brazil) containing four blue-light bulbs and a rotating tray, according to the manufacturer's instructions.

All specimens were immersed in $37^{\circ} \mathrm{C}$ water for $15 \mathrm{~min}$ and polished with 600 to 1,200 grit SiC paper to remove excess material, following ISO4049 specification. ${ }^{8}$ The dimensions of the specimens were verified using a digital caliper (Digimatic caliper, Mitutoyo Corp., Tokyo, Japan).

After storage in distilled water at $37^{\circ} \mathrm{C}$ for $24 \mathrm{~h}$, the specimens were submitted to the three-point bending test in a universal testing machine (EMIC
DL 2000, São José dos Pinhais, PR, Brazil) at a crosshead speed of $0.5 \mathrm{~mm} / \mathrm{min}$ until fracture. The flexural strength values $\left(\sigma_{\mathrm{f}}\right)$, in $\mathrm{MPa}$, were calculated as follows:

$$
\begin{aligned}
& \sigma_{\mathrm{f}}=3 \mathrm{PL} / 2 \mathrm{wb}^{2} \\
& \text { where: } \\
& \mathrm{P} \text { is the fracture load }(\mathrm{N}) \text {; }
\end{aligned}
$$

$\mathrm{L}$ is the distance between the supporting rollers (20 mm);

$\mathrm{w}$ is the specimen height (in $\mathrm{mm}$ );

$\mathrm{b}$ is specimen width (in $\mathrm{mm}$ ).

Knoop hardness $(\mathrm{H})$ was measured on the specimens' fragments $(n=10)$ resultant from the flexural strength test. Three indentations (load of $100 \mathrm{~g}$, dwell time of $15 \mathrm{~s}$ ) were made in each specimen and the diagonals were measured with an optical microscope (HMV-2T, Shimadzu Corporation, Tokyo, Japan) using $400 \mathrm{X}$ magnification. Knoop hardness was calculated as follows (ASTM E384):

$\mathrm{H}=14.2 \mathrm{P} / \mathrm{l}^{2}$

where:

$\mathrm{P}$ is the applied load $(0.1 \mathrm{~kg})$;

$\mathrm{l}$ is the longest diagonal (in $\mathrm{mm}$ ) of the diamond shaped indent.

The results were statistically analyzed using analysis of variance (ANOVA) and Tukey's test at a significance level of 5\%. Pearson's correlation test was used to determine the relationship between the two properties. 


\section{Results}

The mean values and standard deviations $(\mathrm{MPa})$ of flexural strength $\left(\sigma_{\mathrm{f}}\right)$ and hardness $(\mathrm{H})$, and statistical grouping, are shown in Table 2.

The mean $\sigma_{f}$ values were significantly different for all the tested groups. The direct composite systems presented statistically higher mean $\sigma_{\mathrm{f}}$ values than the indirect composites $(\mathrm{p}<0.05)$. The D250 composite exhibited the highest $\sigma_{\mathrm{f}}$ values $(135.4 \pm 17.6$ $\mathrm{MPa}$ ) and the IVM composite exhibited the lowest $\sigma_{\mathrm{f}}$ values $(73.1 \pm 4.9 \mathrm{MPa})$.

The direct composite systems showed the highest $\mathrm{H}$ mean values. The mean $\mathrm{H}$ value of $\mathrm{D} 250$ was statistically greater than that of D350 ( $p<0.05)$, which was also significantly greater than the mean $\mathrm{H}$ values of ISin and IVM $(\mathrm{p}<0.05)$. There was no significant difference between the mean $\mathrm{H}$ values of the indirect systems $(\mathrm{p} \geq 0.05)$.

The correlation test showed a high positive correlation $(r=0.91)$ between the mean $\sigma_{\mathrm{f}}$ and $\mathrm{H}$ values of the materials examined.

\section{Discussion}

The Sinfony (3M-ESPE) and VitaVM LC (Vita) indirect composite systems could be classified as intermediate laboratory composite resins since they have lower percentage of inorganic content $(50 \mathrm{wt} \%$ and $45-48 \mathrm{wt} \%$, respectively) and lower values for the mechanical properties evaluated than expected for second-generation systems..$^{2,3}$

The direct composite systems examined produce higher mean flexural strength and hardness values than the indirect composites, confirming the first study hypothesis. These results are in agreement with previous studies. ${ }^{4,5,9,10}$

Cesar et al. ${ }^{4}$ (2001) evaluated the flexural strength, flexural modulus and hardness of four indirect composite systems (Artglass, Belleglass, Sculpture and Targis) and one direct composite system (Z100). Their results partially agree with those of the present study because Z100 showed the highest mean hardness values, although this material presented a mean flexural strength value similar to that of the indirect composite systems (Artglass, Targis and Sculpture).

A previous study showed that the mean wear val- ue of the indirect composites was significantly greater than the wear of Z100. In addition, the authors reported that Targis and Z100 showed a significantly greater elastic modulus than Artglass old formula and Vita Zeta LC, and Z100 showed a greater mean fracture strength value than Artglass and Vita Zeta LC. ${ }^{10}$

Another study investigated the mechanical properties of a direct composite resin (Z100), a feldspatic porcelain (Noritake) and three indirect composites (Artglass, Solidex and Targis). The porcelain showed the greatest mean hardness value, followed by Z100. Solidex and Z100 showed greater mean compressive strength values than the other materials tested. ${ }^{9}$

Soares et al. ${ }^{5}$ (2005) evaluated the hardness and diametral tensile strength of two direct composites (TPH Spectrum and Filtek P60) and one indirect system (Solidex). The authors also reported that the direct composites showed better mechanical properties than the indirect composite system.

The objective of a secondary polymerization is to maximize the degree of conversion of composites in order to improve mechanical and physical properties, durability, solvent resistance and biocompatibility. ${ }^{11}$ The presence of unpolymerized monomer in the matrix negatively affects the properties of composite materials and may induce surface degradation and discoloration. ${ }^{12,13}$ The additional curing allows higher mobility and reactivity of free radicals formed by light irradiation or by thermal decomposition with an increase in collision probability among the unreacted active groups. ${ }^{14-16}$ When the composite is heated to a temperature above its glass transition, there is an increase in the molecular mobility of the polymer chains. Therefore, it may be possible to further the chemical reaction by enhancing the molecular mobility of existing free radicals and other reactive species. ${ }^{8}$

The above rationale was used by some authors to improve the mechanical properties of composite materials. Freiberg, Ferracane ${ }^{11}$ (1998) showed improvement of fracture toughness, elastic modulus, flexural strength and hardness of composites when increasing the degree of conversion due to additional polymerization. Wendt ${ }^{16}(1987)$ and Soares et al. ${ }^{5}$ (2005) also concluded that an increase in the de- 
gree of conversion improves composites' mechanical properties, such as diametral tensile strength and hardness. Reinhardt et al. ${ }^{17}$ (1994) observed an $11 \%$ increase in flexural strength when a secondary curing procedure was used.

The above results and rationale are indications of improvement in the properties of indirect composite resin systems, but do not mean that indirect composites have a better clinical performance than direct composite systems. An improvement in the degree of conversion itself does not necessarily result in better mechanical properties, because these are also related to other factors, such as resin composition, ${ }^{18}$ filler content, particle size and distribution. $3,9,10,12,17,19-21$

The filler content could be an important factor when evaluating physical and mechanical properties of different composite materials. Li et al. ${ }^{20}$ (1985) reported that increasing the filler content resulted in greater hardness, compressive strength, and stiffness, while water sorption decreased.

Chung $^{19}(1990)$ observed a positive relation between volume fraction of filler and diametral tensile strength and hardness. But no correlation was observed between the degree of conversion and the mechanical properties evaluated. Neves et al. ${ }^{12}$ (2002) also concluded that the filler content directly affects the hardness values.

Other studies also investigated the association

\section{References}

1. Roulet JF. Benefits and disadvantages of tooth-coloured alternatives to amalgam. J Dent. 1997;25(6):459-73.

2. Touati B. The evolution of aesthetic restorative materials for inlays and onlays: a review. Pract Periodontics Aesthet Dent. 1996;8(7):657-66; quiz 668.

3. Touati B, Aidan N. Second generation laboratory composite resins for indirect restorations. J Esthet Dent. 1997;9(3):10818.

4. Cesar PF, Miranda Jr. WG, Braga RR. Influence of shade and storage time on the flexural strength, flexural modulus, and hardness of composites used for indirect restorations. J Prosthet Dent. 2001;86(3):289-96.

5. Soares CJ, Pizi EC, Fonseca RB, Martins LR. Mechanical properties of light-cured composites polymerized with several additional post-curing methods. Oper Dent. 2005;30(3):38994. between the mechanical properties of composites and the difference in filler volume. The authors reported that the materials with higher filler volumes showed better mechanical properties. ${ }^{9,17,21}$

These observations seem to be confirmed by the results of this study, especially when the materials' filler volumes (Table 1) are compared with the mean $\sigma_{\mathrm{f}}$ and $\mathrm{H}$ values (Table 2). The composite resins with higher filler contents, D250 (82wt\%) and D350 $(78.5 \mathrm{wt} \%)$, showed significantly higher mean $\sigma_{\mathrm{f}}$ and $H$ values than the composites with lower filler contents, ISin $(50 \mathrm{wt} \%)$ and IVM $(45-48 \mathrm{wt} \%)$. Therefore, the filler content influenced the mechanical properties of the composite resins investigated.

The second study hypothesis was also confirmed, since there was a high positive correlation $(r=0.91)$ between the $\sigma_{\mathrm{f}}$ and $\mathrm{H}$ properties of the composites systems examined. This correlation can be explained because the $\sigma_{f}$ provides information on the bulk properties and the $\mathrm{H}$ measures the materials surface properties, ${ }^{22}$ and both properties are clinically relevant in characterizing a restorative material.

\section{Conclusion}

The direct composite systems examined had higher mean $\sigma_{\mathrm{f}}$ and $\mathrm{H}$ values than the indirect composites, and the mean values of these properties were positively correlated $(r=0.91)$, confirming the study hypotheses.

6. Kakaboura A, Rahiotis C, Zinelis S, Al-Dhamadi YA, Silikas $\mathrm{N}$, Watts DC. In vitro characterization of two laboratoryprocessed resin composites. Dent Mater. 2003;19(5):393-8.

7. International Standards Organization. ISO 4049 Dentistry - Polymer-based filling, restorative and luting materials; 2000.

8. Ferracane JL, Condon JR. Post-cure heat treatments for composites: properties and fractography. Dent Mater. 1992;8(5):290-5.

9. Da Fonte Porto Carreiro A, Dos Santos Cruz CA, Vergani CE. Hardness and compressive strength of indirect composite resins: effects of immersion in distilled water. J Oral Rehabil. 2004;31(11):1085-9.

10. Reich SM, Petschelt A, Wichmann M, Frankenberger R. Mechanical properties and three-body wear of veneering compos- 
ites and their matrices. J Biomed Mater Res A. 2004;69(1):659.

11. Freiberg RS, Ferracane JL. Evaluation of cure, properties and wear resistance of Artglass dental composite. Am J Dent. 1998;11(5):214-8.

12. Neves AD, Discacciati JA, Orefice RL, Jansen WC. Correlation between degree of conversion, microhardness and inorganic content in composites. Braz Oral Res. 2002;16(4):34954.

13. Satsukawa H, Koizumi H, Tanoue N, Nemoto M, Ogino T, Matsumura H. Properties of an indirect composite material polymerized with two different laboratory polymerizing systems. Dent Mater J. 2005;24(3):377-81.

14. Cook WD, Johannson M. The influence of post-curing on the fracture properties of photo-cured dimethacrylate based dental composite resin. J Biomed Res. 1987;21(8):979-89.

15. Ho CT, Vijayaraghavan TV, Lee SY, Tsai A, Huang HM, Pan LC. Flexural behaviour of post-cured composites at oral-simulating temperatures. J Oral Rehabil. 2001;28(7):658-67.

16. Wendt Jr. SL. The effect of heat used as secondary cure upon the physical properties of three composite resins.
II. Wear, hardness, and color stability. Quintessence Int. 1987;18(5):351-6.

17. Reinhardt JW, Boyer DB, Stephens NH. Effects of secondary curing on indirect posterior composite resins. Oper Dent. 1994;19(6):217-20.

18. Wendt Jr. SL, Leinfelder KF. The clinical evaluation of heat-treated composite resin inlays. J Am Dent Assoc. 1990;120(2):177-81.

19. Chung KH. The relationship between composition and properties of posterior resin composites. J Dent Res. 1990;69(3):8526.

20. Li Y, Swartz ML, Phillips RW, Moore BK, Roberts TA. Effect of filler content and size on properties of composites. J Dent Res. 1985;64(12):1396-401.

21. Manhart J, Kunzelmann KH, Chen HY, Hickel R. Mechanical properties of new composite restorative materials. J Biomed Mater Res. 2000;53(4):353-61.

22. Callister Jr WD. Materials Science and Engineering: an Introduction. $5^{\text {th }}$ ed. New York: John Wiley \& Sons; 2000. 